\title{
Transmission Electron Microscopy on Magnetic Phase Transformations in Functional Materials
}

\author{
Y. MURAKAMI, T. YANO, D. SHINDO, R. KAINUMA, and T. ARIMA
}

DOI: $10.1007 / \mathrm{s} 11661-007-9238-\mathrm{y}$

(C) The Minerals, Metals \& Materials Society and ASM International 2007

Erratum to: METALLURGICAL AND MATERIALS TRANSACTIONS A, Vol. 38A, No. 4, April 2007

\section{DOI: 10.1007/s11661-007-9235-1}

FOLLOWING are updates to the original article:

1. Y. Murakami's correct academic title is Associate Professor.

2. The corrected caption for figure 4 is as follows: Fig. 4- Tip portion of the double probe piezodriving holder.

3. The last paragraph under the heading "B. Examinations on the Phase Identification in Hole-Doped Manganites" is updated as follows:

As demonstrated in this study, our new TEM-based system is available in the electric and magnetic phase identification in a nanoscale area. In addition, because this system can supply a high density current (e.g., $10^{5} \mathrm{~A} / \mathrm{cm}^{2}$ or higher) to a nanoscale area, it is possible to examine the current-induced change in domain structures by TEM.

4. Reference 7 is updated as follows: T. Kakeshita, T. Takeuchi, T. Fukuda, T. Tsujiguchi, T. Saburi, R. Oshima, and S. Muto: Appl. Phys. Lett., 2000, vol. 77, pp. 1502-04.

5. Reference 9 is updated as follows: Y. Murakami, D. Shindo, T. Kobayahsi, K. Oikawa, R. Kainuma, and K. Ishida: Mater. Sci. Eng., A, 2006, vol. 43840, pp. $1050-53$.

Y. MURAKAMI, Associate Professor, T. YANO, Student, D. SHINDO, R. KAINUMA, and T. ARIMA, Professors, are with the Institute of Multidisciplinary Research for Advanced Materials, Tohoku University, Sendai 980-8577, Japan. Contact e-mail: murakami@ tagen.tohoku.ac.jp

The online version of the original article can be found under doi:10.1007/s11661-007-9235-1.

Article published online July 10, 2007. 